\title{
DO PALCO À FLORA, A PREGNÂNCIA DE UM IMAGINÁRIO A Inteligência das flores de Maurice Maeterlinck ${ }^{1}$ Marc Quaghebeur² Tradução de Cristina Robalo Cordeiro ${ }^{3}$
}

RESUMO: Considera-se com frequência como um aparte a produção de Maurice Maeterlinck dedicada aos fatos naturais. A coerência dos livros deste ciclo, no interior do conjunto da obra, merece, no entanto, um olhar atento. Publicado na metade da vida do futuro Prêmio Nobel, L'Intelligence des fleurs [A Inteligência das Flores] (1907) prova ser assim bem mais que uma pura descrição botânica. O que o torna singular é o emaranhado de uma tal descrição natural com as assombrações do imaginário maeterlinckiano, que são além disso aquelas do idealismo finissecular. Este estudo faz surgir numerosos exemplos de descrições que se acreditaria tiradas dos dramas do autor de Pelléas.

PALAVRAS-CHAVE: Narrativa de Natureza; Fim de Século; Idealismo; Analogia; Literatura Francófona.

\footnotetext{
${ }^{1}$ Publicado originalmente em francês sob o título "Foncier, l'imaginaire de Maeterlinck face à la nature" (in MUSSCHOOT, SCHOENTJES, 2013).

2 Doutor em Filosofia e Letras com a tese L'œuvre nommée Arthur Rimbaud (1975), ensaísta, poeta e escritor, Marc Quaghebeur é diretor dos Arquivos e Museu da Literatura em Bruxelas. Ele é autor de vários livros de referência dedicados à literatura belga francófona e ao simbolismo, dentre os quais o mais recente é intitulado Histoire Forme et Sens en Littérature. La Belgique francophone. L'engendrement (1815/1914) (2015).

${ }_{3}$ Professora Catedrática da Faculdade de Letras da Universidade de Coimbra.
} 


\section{DE LA SCENE A LA FLORE, UN IMAGINAIRE FONCIER. L'INTELLIGENCE DES FLEURS DE MAURICE MAETERLINCK}

RÉSUMÉ : On considère souvent comme un à côté la production de Maurice Maeterlinck consacrée aux faits naturels. La cohérence des livres de ce cycle, à l'intérieur de l'ensemble de l'œuvre, mérite pourtant un regard attentif. Publié au mitan de la vie du futur Prix Nobel, L'Intelligence des fleurs (1907) s'avère ainsi bien davantage qu'une pure description botanique. Ce qui en fait la singularité, c'est le tressage d'une telle description naturelle avec les hantises de l'imaginaire maeterlinckien, qui sont en outre celles de l'idéalisme Fin de siècle. Cette étude fait surgir de nombreux exemples de descriptions qu'on croirait tirées des drames de l'auteur de Pelléas.

MOTS-CLÉS : Récit de nature; Fin de siècle; Idéalisme; Analogie ; Littérature francophone.

É comum, a propósito de Maeterlinck, falarmos do Primeiro e do Segundo Teatros e esquecermos o Terceiro e mesmo o Quarto4. De igual modo, acontecenos opor a figura de Polidoro Maeterlinck, pai do escritor, proprietário abastado e amante de uma natureza algo liberal à mãe do escritor, mais pietista e mais rigorista. E também assim procedemos no que toca à educação do jovem no seio do cristianismo negro dos jesuítas do século XIX.

Se é inegável que a obra conheceu evoluções significativas, e se a figura de Maeterlinck sempre revelou profundas contradições, mas também uma grande vontade de resolução ou de superação dessas tensões, não é menos certo que, numa obra com a qual a vida coincide bem mais do que na maioria dos escritores (e tanto mais que o autor de $O$ Pássaro azul não conheceu nunca preocupações financeiras), manifesta-se uma profunda continuidade senão mesmo um retomar incessante de certos elementos recorrentes (ainda que diferentemente dispostos). A este aspecto da paisagem literária foram sensíveis Joseph Hanse, Robert Vivier ou Roland Mortier no volume do centenário publicado na Renascença do livro (HANSE; VIVIER, 1962). É também esta a linha para a qual se orienta, com outros instrumentos de abordagem, a tese de Nancy Delay sobre o Segundo Teatro, no sentido estrito ${ }^{5}$, ao pôr em causa certos julgamentos radicais de Gaston Compère $^{6}$, como a redescoberta unívoca da modernidade do primeiro teatro.

\footnotetext{
"Examinei este Quarto Teatro em "Le dernier Maeterlinck" (2002).

${ }^{5}$ Além da sua tese defendida em Bolonha Vers le régime nocturne de l'imaginaire : Le théâtre d'entre-deux-siècles de Maurice Maeterlinck, Nancy Delay publicou nomeadamente: "Le premier symbole maeterlinckien" (2000); "L'évolution de l'esthétique symboliste de Maeterlinck dans l'entre-deux-siècles" (2001, p. 9-28); “Aux Sources de Monna Vanna” (1994, p. 237-270), também publicado na internet; "Histoires de Barbe-Bleue à ne jamais dormir debout. Lecture comparative du conte chez Perrault et Maeterlinck" (1997, p. 59-90) - recensão crítica deste artigo de M. Christian Berg in Annales de la Fondation Maeterlinck, Gand, n³1 (1997, p. 282-
} 
Um texto emblemático do segundo período, A Inteligência das flores, permite abordar esta coerência profunda. Ao lado de numerosas considerações botânicas e botanistas, nele encontramos uma retomada, subtil mas omnipresente, de numerosos motivos desta obra, o que explica sem dúvida que $A$ Inteligência das flores seja uma jóia comparável a O Pássaro azul ou a Pelléas e Mélisande.

Publicado em 1907, isto é, a meio da vida do escritor - e dois anos antes da emergência pública de $O$ Pássaro azul -, o texto comporta uma centena de páginas estritamente consagradas à Inteligência das flores, mas às quais vieram juntar-se dois ensaios, muito mais breves, Os Perfumes e A Medida das horas (no qual o motivo da ampulheta, que se tornará um dos títulos da obra, é evidentemente retomado). Nestas duas contribuições de menor importância, e mesmo se certas metáforas poéticas lhes ornamentam o percurso, não se trata de 0 produzir, mas mais precisamente de o ornamentar e ilustrar. Ora, em $A$ Inteligência das flores, os motivos que procurarei pôr em relevo estão profundamente imersos no texto, dando-lhe um alcance que vai muito além da pura descrição botânica.

Assim, nos primeiros capítulos do livro (MAETERLINCK, 1939) 7, que precedem a descrição propriamente dita de uma série de plantes e flores, verificamos que, desde a primeira página, o que fascina o autor na vida das flores é "o esforço da vida vegetal em direcção à luz e em direcção ao espírito" (p. 1). Neste mesmo primeiro capítulo, Maeterlinck escreve que todas as flores "se empenham na realização da sua obra” (p. 2). É pois para esta obsessão geral da luz, que entretece toda a obra (lembremos a primeira das duas cenas do poço em Pelléas e Mélisande, que Antoine Vitez tão admiravelmente havia posto em cena em Viena), que o livro remete, desde o início, como também para a indicação autotemática de que se trata do desenvolvimento fundamental do trabalho da planta ou da flor, elas próprias metáforas da obra literária.

O segundo capítulo, que não deixa de referir que o néctar da flor é um mensageiro de amor que deve permitir-lhe receber "o beijo do amante longínquo, invisível, imóvel...” (p. 3), designa aliás uma figura fundamental da obra dramática, de que Pelléas é a mais evidente e a mais conhecida incarnação. Contudo, igualmente significativa é a fórmula que descreve o destino fundamental da flor e da planta: "escapar por cima à fatalidade do baixo" e "quebrar a estreita esfera, inventar ou invocar asas, evadir-se o mais longe possível, vencer o espaço onde o destino se encerra, aproximar-se de um outro reino" (p. 4).

Todo o universo de Maeterlinck, qualificado (e com razão) de idealista, é assim trazido desde as primeiras páginas de uma obra que é muito mais do que um

283); "Structure et symboles de l'imaginaire nocturne dans le second théâtre de Maurice Maeterlinck" (2002, p. 198-239).

${ }^{6} \mathrm{O}$ seu trabalho, que valoriza quase exclusivamente o Primeiro Teatro, encontra-se em Le Théâtre de Maurice Maeterlinck (1955) e em Maurice Maeterlinck (1990).

7 Todas as citações reenviam para a reprodução offset (1977) nas Éditions d'aujourd'hui, para a coleção "Les Introuvables", do volume publicado por Fasquelle, em 1939. Os reenvios das citações às páginas desta edição estão indicados no texto depois da citação. 
tratado de botânica, e que deste modo reenvia à obra inteira, em cada uma das suas fases, no que a prende tanto ao mais terrestre quanto a certas situações-chave nas quais o autor coloca as personagens do seu Teatro. Não é, em suma, a expressão indicando que se trata de quebrar a estreita esfera que abre Pelléas com a questão da porta e do limiar, na primeira cena ? E mesmo com o jogo dos círculos concêntricos do castelo e do jardim de que Mélisande não conseguirá sair senão pela morte, e que se efectua numa relação quase mística com a luz entrevista pela janela aberta do quarto virado para o mar.

Igualmente significativos são os comentários do terceiro capítulo, ao lembrarem que o problema da reprodução dos vegetais é o de fugir da "terrível lei de imobilidade absoluta” (p.5). Esta asserção é comentada pelo escritor que relembra que "o pior inimigo da semente, é o cepo paterno" (p. 5), expressão que poderá ser alargada ao espaço familiar no seu conjunto, pois o parágrafo termina pela necessidade de, para cada semente, inventar "um modo bem seu para se evadir da sombra materna" (p. 6). Trata-se pois para as plantas, como para as heroínas de Maeterlinck, de "sacudir o jugo e conquistar o espaço" (p. 6). Tratase, pois, igualmente de "germinar longe dos perigos do lugar natal” (p. 8), o que dá aliás que pensar sobre o itinerário de Maeterlinck de Gand e Oastakker até Médan, Saint-Wandrille, Grasse ou Orlamonde - denominação que, só por si, dispensa comentários.

A descrição das plantas começa, por outro lado, pela de "duas pobres plantas trepadeiras" (p. 9), o que não deixa de fazer lembrar os miseráveis que encontramos tanto em A Princesa Maleine quanto em Pelléas e Mélisande. No capítulo seguinte, que se interessa por um vegetal de uma espécie bem diferente o próprio nome remete para as grandes personagens dos universos de Maeterlinck, pois se trata do loureiro -, o comentário do escritor vem relembrar que a árvore que descreve - velha Arkel vegetal numa posição singular, arriscada e, poder-se-á dizer, genial - projectou "as cegas raízes à longa e penosa procura da água precária e do húmus” (p. 13).

Constatamos assim como, numa altura em que o autor não entrara ainda no cerne do tema (que andará nomeadamente em torno das mil e uma variedades de orquídeas), a sua descrição e o seu comentário botânicos se produzem através da retomada e do encadeamento dos grandes motivos que estruturam desde o início tanto as obras dramáticas quanto as obras poéticas de Maeterlinck. Não serão os "espantos deliciosos da Sensitiva" (p. 15), comumente designada por "Mimosa púdica” (p. 16), o equivalente das esperas das princesas e das personagens das Quinze canções, visando "uma agitação rítmica, quase cronométrica e incessante" (p. 16), que não deixa de se aparentar com uma dramaturgia que foi muitas vezes qualificada de teatro estático (mas infinitamente vibrátil)?

Igualmente significativo é, nestas primeiras páginas do livro, e numa altura em que o autor se prepara para abandonar as plantas aquáticas, o comentário que lembra que os homens são os "últimos surgidos sobre a terra", não podendo assim 
senão encontrar "simplesmente o que sempre existiu" e refazer "como crianças maravilhadas a estrada que a vida havia feito antes de nós" (p. 21). Desde esta frase, dois anos antes da sua emergência no grande público e nos palcos, $O$ Pássaro azul claramente se perfila.

No momento em que anunciava que ia abandonar as plantas aquáticas, Maeterlinck a elas regressa em força, com a valisnéria, cuja existência compara a uma "espécie de sonolência, até à hora nupcial em que aspira a uma vida nova" (p.22). Não é, uma vez mais, um condensado de Pelléas e de muitas outras peças? E o autor prossegue, recordando que, sendo as hastes destas plantas demasiado curtas, "não atingirão nunca o reino da luz, o único em que pode perfazer-se a união do estame e do pistilo" (p.23). "Imaginai, continua o escritor, [...] o drama deste desejo, o incessível em que tocamos, a fatalidade transparente, o impossível sem obstáculo visível!..." (p.23). Lê-se, imediatamente a seguir: "Teriam os machos o pressentimento da sua decepção? Seja como for, fecharam no coração uma bolha de água como se fecha na alma um pensamento de libertação desesperada. Dir-se-ia que hesitam um instante; depois, num esforço magnífico, [...] rompem deliberadamente o laço que os prende à existência [...]" e ao auge que “com incomparável élan, por entre pérolas de alegria" (p.23), acedem à existência que os deixa "feridos de morte mas radiosos e livres" (p.24). Não encontraremos aqui, metaforicamente, a grande cena do acto 4 de Pelléas e Mélisande, que conduz à morte do príncipe? Com a diferença apenas de que ela aqui se opera através de um movimento inverso (no fundo do poço, mas depois do akmé da revelação e da sua declaração).

Este oitavo capítulo, Maeterlinck fecha-o com uma das antíteses que a obra inteira constantemente tece, considerando que, na maioria das espécies, é nela e não nos seus indivíduos que reside o génio enquanto "nos homens apenas existe emulação real entre duas inteligências" (p.25). Não me alongarei nas descrições, muitas vezes admiráveis e sempre apaixonantes, das diferentes estratégias das plantas para levar os insectos a transportar o pólen, descrições que se focalizam em diferentes tipos de orquídeas. Mas continuarei a insistir sobre a tessitura, no texto, de elementos fundamentais que constituem o universo de Maeterlinck e se encontram também nas suas ficções, e que faz sem dúvida deste pequeno livro uma jóia que a memória dos homens conserva para além da pura descrição botânica que contém.

O décimo capítulo fala assim, na descrição de Nigela de Damas (também chamada Cabelos de Vénus, Diabo nas silvas ou Bela de cabelos soltos), do "drama sem palavras e sem desfecho previsível, da espera impotente, inútil, imóvel” (p.37). Esta fórmula condiz com bastantes sequências do teatro de Maeterlinck. Com o passar do tempo contudo, o esplendor das flores empalidece "e o orgulho das grandes rainhas, sob o peso da vida, parece enfim curvar-se" (p.37). É então que elas vão "obedecer à palavra de ordem secreta e irresistível do amor que julga suficiente a prova, de um movimento concertado e simétrico, 
comparável às harmoniosas parábolas de um quíntuplo jacto de água que cai de novo no seu lago" (p.37). Todas podem então colher "nos lábios dos seus humildes amantes, o pó de ouro do beijo nupcial" (p.38). No capítulo seguinte, Maeterlinck insiste além disso no facto de que não pretende prender-se "senão à flor verdadeiramente flor, à flor propriamente dita, considerada insensível e inanimada" (p.39). E acrescenta: "ei-la sozinha em cena, como uma magnífica princesa dotada de razão e de vontade” (p. 39).

Neste pequeno volume, é claro que o corpus propriamente dito da descrição das orquídeas oferece menos rastos dessa tessitura contante que demonstra a coerência profunda da obra de Maeterlinck. No entanto, ele não deixa de falar "da alma da flor" e "dos hábitos mentais daquela que está acima de todas as outras na arte de obrigar a abelha e a borboleta a fazerem exactamente o que ela deseja, na forma e no tempo prescritos" (p. 59). A dimensão da natureza e do destino que marcou os jovens anos do escritor assim se perfila, e de um modo que lhe permite ainda abrir-se ao feérico - e logo à luz que procura.

São numerosas as descrições que insistem nesta lógica quase teleológica, e cuja importância para o Primeiro Teatro foi tantas vezes sublinhada. Como podemos ver, encontra-se inscrita face aos fenómenos vegetais, mas transcrita de outra forma, pois se trata da reprodução da vida e da maravilha dos ciclos naturais. As descrições dos diferentes lugares onde se colocam os aglomerados de pólen, as hastes, as bolas viscosas e os discos membranosos integram-se contudo nesta teleologia fundamental e portadora do maravilhoso, que desabrocha cada vez mais claramente nesta fase da criação de Maeterlinck. É contudo significativo que, no termo do capítulo 16, o escritor escreva, no momento em que constata que uma parte do mistério escapa às possibilidades de descrição humana: "como em todas as coisas, o verdadeiro e grande milagre começa onde o nosso olhar para” (p.66, grifos nossos).

A frase reveste mais importância ainda a partir do momento em que nos reportamos ao papel essencial do olhar em Estufas quentes, como no Primeiro Teatro. Basta pensarmos na incrível ocorrência de palavras e de cenas que se prendem com o olhar em Pelléas e Mélisande, incluindo as obsessões trágicas de Golaud. Deste modo, apercebemo-nos de como as temáticas cujas radículas proliferam em toda a obra se metamorfoseiam também parcialmente, à medida que a obra evolui. Esta é sem dúvida uma das pistas maiores a seguir para uma releitura aprofundada da obra do Prémio Nobel de 1911.

$\mathrm{E}$ isto tanto mais que à medida que $A$ Inteligência das flores avança para a conclusão, os reenvios autotélicos ao funcionamento da obra multiplicam-se, pois esta não faz senão reproduzir as grandes leis da vida e que o homem não faz senão retomar, na criação artística, as grandes formas da natureza. Assim, no início do capítulo 19, Maeterlinck escreve: "Não é exactamente assim, através de nadas, de retomas e de retoques sucessivos que as invenções humanas progridem?” (p.72). Uma tal fórmula aplica-se precisamente à grande arte dos diálogos de Maeterlinck, particularmente no Primeiro Teatro. 
No capítulo seguinte, o que não deixa ainda de remeter para os diferentes momentos da evolução desta obra-vida, Maeterlinck interroga-se: "Se revertêssemos o movimento?" (p.75). E continua, dizendo que "do inesperado sai de repente o desconhecido" (p.76). Quando nos lembramos de que o jovem surrealista Paul Nougé foi um leitor assíduo ${ }^{8}$ de Maeterlinck e um admirador de Georgette Leblanc, não podemos deixar de ser sensíveis a esta fórmula que o animador de Correspondência actualizou radicalmente. Mas Maeterlinck não fizera aqui, como aliás em outros domínios, senão deixar entrever o horizonte ou o esquiço.

O capítulo seguinte (XXI), com toda a lógica - o que prova bem a coerência imaginária das metáforas que estruturam insidiosamente o texto -, retoma a figura do labirinto, a do périplo das crianças em O Pássaro azul, mas também do percurso da Irmã Beatriz, dos corredores de Barba Azul, ou das secretas deambulações de Golaud e de Pelléas nas cavernas e nos corredores do castelo d'Allemonde. Estes labirintos conduzem ao que configurará a trama do capítulo XXI. O autor compara-os a "contos de fadas" (p.80), termos com os quais abre o capítulo que se anuncia como o detonador do elemento conclusivo do livro. Estes contos de fadas podem chegar ao limite do negro, da mesma forma que as figuras de Golaud ou de Barba azul existem para o recordar no universo teatral. O autor fala assim de um lugar "exíguo" cujas "paredes são escorregadias" e "os convidados brutais" (p.82). É que a flor "conhece e explora as paixões dos insectos" (p.83), e que, de uma certa forma, para lá das metáforas talvez exageradamente exacerbadas, a obra inteira de Maeterlinck se coloca sob este signo. Uma obra que não deixou por vezes, e nomeadamente nos seus primórdios, de recorrer às "complicações fantásticas" (p.84) de que também encontramos rasto neste capítulo.

Não será assim a obra de Maeterlinck, como acontece com muitas plantas e flores, uma criação "de imaginários tipo que julgamos fixados, e que não são provavelmente senão os representantes de uma mesma flor que continua a modificar lentamente os seus órgãos, segundo lentas circunstâncias” (pp.85-86)? O que esta obra procura decididamente, e que encontramos no comentário sobre a vida das flores e reaparece no final do livro, é um "horizonte purificado" (p.95), que Maeterlinck define como o de "duas ou três imagens inocentes, invariáveis e frescas, que gostaríamos de levar connosco no último sono, se é verdade que uma imagem possa atravessar o limiar que separa os nossos dois mundos" (p.95).

Esta questão da imagem - e da imagem do entre dois mundos - é fundamentalmente a chave do teatro de Maeterlinck. Tanto nas incarnações das suas heroínas e do conjunto das quatro fases do seu Teatro quanto na emergência genial das grandes Estufas quentes em estrofes, ou na melodia mais íntima e dilacerante das Canções. Não é assim - e estas expressões encontram-se também

\footnotetext{
${ }^{8}$ Ninguém parece ter notado que uma das Publicité(s) transfigurée(s), reproduzida na página 70 de Paul Nougé Fragments (1997), e na página 317 de L'Expérience continue (NOUGÉ, 1981), constitui uma sutil retomada da grande cena da cabeleira no ato III de Pelléas et Mélisande.
} 
no capítulo XXVII - que se dispõe tanto a luta "contra a massa pesada, enorme e obscura do seu ser, quanto a tensão "em direcção a uma vida mais ardente, mais complexa, mais nervosa, mais espiritual” (p.99)?

Maeterlinck chega assim, no capítulo XXVIII, à criação de um mito que configura o mito da caverna de Platão e modifica também, de certa forma, o mito das cavernas que se encontram no castelo d'Allemonde. Encadeando sempre frases e metáforas em torno da temática do olhar, como da obsessão da luz, Maeterlinck imagina uma caverna na qual "os homens se encontrassem prisioneiros desde o nascimento. Não lamentariam assim a luz, não a tendo jamais visto; não seriam cegos, os seus olhos não estariam mortos, mas, nada tendo para olhar, tornar-se-iam provavelmente $o$ órgão mais sensível ao tacto" (p.101). Aqui encontramos claramente a questão da imagem e do entre dois mundos que acaba de ser evocada. Os homens de que aqui falamos, escreve Maeterlinck, poderiam assim tirar partido "de coisas que não haviam sido criadas para a noite!...” (p.101).

Pois que vivemos [escreve Maeterlinck] numa caverna deste género, não é interessante constatarmos que o poder que nela nos colocou age com frequência sobre alguns domínios importantes, como nós próprios agimos? São lampejos no nosso subterrâneo que nos mostram que não nos enganámos quanto ao uso de todos os objectos que nele se encontram; e alguns desses lampejos são-nos trazidos pelos insectos e pelas flores (p.102).

Assim poderíamos enfim descobrir "a natureza e o destino verdadeiros de utensílios e aparelhos que [os homens] teriam [até então] procurado adaptar o melhor possível às incertezas da sombra" (p. 101).

Mas quando se trata de falar do natural, esse domínio privilegiado do pai e da infância, as grandes metáforas, inquietações e interrogações reveladas pelo Primeiro Teatro permanecem operantes. Agarram-se a realidades que permitem esperar sair desse reino das sombras com o qual se identifica a vida no Primeiro Teatro. O natural, com o qual a obra de Maeterlinck pretende doravante conformar profundamente o essencial do destino humano, a ele não se limita inteiramente. "Não era o nosso sonho específico de justiça e de piedade" (p.103), escreve com efeito o autor. Este sonho constitui, também ele, um dos dados maiores da obra do autor do Massacre dos inocentes.

A Inteligência das flores, que se aproxima do fim, não deixa de fazer alusão à analogia, que estrutura a percepção e a restituição do mundo do escritor, como de numerosos autores belgas de língua francesa. O livro evoca também a evolução do mundo de então. Além disso, reenvia ao que se passa entre o seu Primeiro e o seu Segundo Teatros. Com efeito, Maeterlinck escreve: "Não convivamos com deuses inacessíveis, mas com vontades veladas e fraternas, que se trata de surpreender e 
de dirigir" (p.105). Estas, cujo sonho é maravilhosamente esboçado em O Pássaro Azul, serão profundamente mutiladas pela matança de 1914-1918 e conduzirão ao Terceiro Teatro. Como a catástrofe de 1940, ao Quarto. Com A Inteligência das flores e $O$ Pássaro Azul, Maeterlinck pensava ter atingido aquele ponto de equilíbrio que explica em parte a "graça" deste texto.

\section{REFERÊNCIAS BIBLIOGRÁFICAS}

COMPÈRE, Gaston. Le Théâtre de Maurice Maeterlinck. Bruxelles : Palais des Académies, 1955.

COMPÈRE, Gaston. Maurice Maeterlinck. Paris : La Manufacture, 1990.

DELAY, Nancy. "Aux Sources de Monna Vanna », in Textyles, n. 11. Bruxelles, 1994, p. 237-270.

DELAY, Nancy. «Histoires de Barbe-Bleue à ne jamais dormir debout. Lecture comparative du conte chez Perrault et Maeterlinck » in Cahiers francophones d'Europe Centre-Orientale, 7-8, t.1. Pécs/Vienne, 1997, p. 59-90.

DELAY, Nancy. « Le premier symbole maeterlinckien », in Correspondance, $\mathrm{n}^{\circ} 5 \mathrm{O}$, Cáceres, 2000.

DELAY, Nancy. "L'évolution de l'esthétique symboliste de Maeterlinck dans l'entre-deux-siècles » in Les lettres belges au présent : actes du congrès des romanistes allemands : université d'Osnabrück, du 27 au 30 septembre 1999. Frankfurt : Peter Lang, 2001, p. 9-28

DELAY, Nancy. « Structure et symboles de l'imaginaire nocturne dans le second théâtre de Maurice Maeterlinck » in QUAGHEBEUR, Marc. Présence/Absence de Maeterlinck. Bruxelles : AML Éditions, Labor, 2002, p. 198-239.

HANSE, Joseph Hanse ; VIVIER, Robert (éds). Maurice Maeterlinck 1862-1962. Bruxelles : La Renaissance du livre, 1962.

MAETERLINCK, Maurice. L'Intelligence des Fleurs. Paris : Fasquelle, 1939.

NOUGÉ, Paul. Fragments. Bruxelles : Espace Nord nº $7,1997$. 
NOUGÉ, Paul. L'Expérience continue. Lausanne : L’Âge d'homme, 1981.

QUAGHEBEUR, Marc. "Foncier, l'imaginaire de Maeterlinck face à la nature ». MUSSCHOOT, Anne Marie; SCHOENTJES, Pierre (éds). Maeterlinck en de natuur = Maeterlinck face à la nature. Gent: Koninklijke Academie voor Nederlandse Taal-en Letterkunde ; Bruxelles : Académie royale de Langue et de Littérature françaises, 2013, p. 69-76.

QUAGHEBEUR, Marc. «Le dernier Maeterlinck ». In: QUAGHEBEUR, Marc (éd.) Présence/Absence de Maeterlinck. Bruxelles : Labor (Archives du futur), 2002, p. 200-284. 